\title{
Interferência de plantas daninhas na cultura do sorgo cultivado em safrinha ${ }^{1}$
}

\author{
Paulo Henrique Ramos Cabral ${ }^{2}$, Adriano Jakelaitis², \\ Isabella Sichierski Cardoso², Vinícius Tavares de $\mathrm{Araújo}^{2}$, Evandro César Fernandes Pedrini ${ }^{2}$
}

\begin{abstract}
Weed interference on off-season sorghum crop

Sorghum has a great importance in the world economy as an energy source for food and feed. In the southwest Goiás State, although this culture has a high productive potential, its yield is low, mainly due to the interference of inadequate weed management. This research aimed at determining the periods of weed interference on off-season sorghum crop, in Rio Verde, Goiás State, Brazil. Treatments consisted of ten periods of initial control, in which the crop was kept free of weeds, and ten periods of initial coexistence with weeds. Both the initial periods of control or coexistence, after the crop emergence, were: $0-0,0-7,0-14,0-21,0-28,0-35,0-42,0-49$, $0-56$ and 0 -harvest (112 days after emergence - DAE). The most important weed species present in the experimental area were Amaranthus lividus, Commelina benghalensis, Bidens pilosa, Sida rhombifolia, Urochloa decumbens, Digitaria horizontalis and Portulaca oleracea. The presence of weeds reduced plant height, stem diameter, grain yield and one thousand grain weight of sorghum, with a higher interference degree for increasing periods of mutual coexistence between the weed community and sorghum. For a $5 \%$ tolerance in the reduction of sorghum yield, it was concluded that the period before the interference was up to $23 \mathrm{DAE}$, the total period of interference prevention up to $42 \mathrm{DAE}$ and the critical period of interference prevention from 23 to 42 DAE.
\end{abstract}

KEY-WORDS: Sorghum bicolor L.; Poaceae; weed community.

\section{INTRODUÇÃO}

O sorgo (Sorghum bicolor L.) é uma espécie de origem africana, pertencente à família Poaceae. Situa-se em quinto lugar, entre os cereais mais cultivados no mundo, sendo suplantado apenas pelo trigo, arroz, milho e cevada (Fornasieri Filho \& Fornasieri 2009).

Apresenta metabolismo fotossintético $\mathrm{C}_{4}$, que confere à espécie alta produção de matéria seca e características específicas de tolerância à seca e ao

\section{RESUMO}

O sorgo apresenta grande importância na economia mundial, como fonte de energia para a alimentação humana e animal. No sudoeste Goiano, apesar de esta cultura apresentar alto potencial produtivo, a produtividade é baixa, fato atribuído, em grande parte, à interferência do manejo inadequado de plantas daninhas. Objetivou-se, nesta pesquisa, determinar os períodos de interferência de plantas daninhas sobre a cultura do sorgo cultivado em safrinha, no município de Rio Verde (GO). Os tratamentos foram constituídos por dez períodos de controle inicial, nos quais a cultura foi mantida livre da comunidade infestante, e dez períodos de convivência inicial da cultura com as plantas daninhas. Os períodos iniciais de controle ou de convivência, após a emergência da cultura, foram: 0-0, 0-7, 0-14, 0-21, 0-28, 0-35, 0-42, 0-49, 0-56 e 0 -colheita (112 dias após a emergência - DAE). As espécies de plantas daninhas mais importantes presentes na área experimental foram Amaranthus lividus, Commelina benghalensis, Bidens pilosa, Sida rhombifolia, Urochloa decumbens, Digitaria horizontalis e Portulaca oleracea. A presença de plantas daninhas reduziu a altura de plantas, diâmetro de colmo, rendimento de grãos e a massa de mil grãos de sorgo, sendo maior o grau de interferência com o aumento dos períodos de convivência mútua entre a comunidade infestante e o sorgo. Considerando-se $5 \%$ de tolerância na redução da produtividade do sorgo, concluiu-se que o período anterior à interferência foi até os $23 \mathrm{DAE}$, o período total de prevenção da interferência até os $42 \mathrm{DAE}$ e o período crítico de prevenção da interferência dos 23 aos 42 DAE.

PALAVRAS-CHAVE: Sorghum bicolor L.; Poaceae; comunidade infestante.

calor, porém, com baixa tolerância ao frio (Fornasieri Filho \& Fornasieri 2009). Estas características permitem ampliar a época de semeadura, que se estende de setembro a março, para as condições do Centro-Sul brasileiro, sendo explorada, frequentemente, em sucessão a culturas precoces de verão, como a soja (Zago 1997).

A produção brasileira de sorgo, na safra 2011/2012, foi de 2.221,9 mil toneladas, em 786,9 mil hectares cultivados, com rendimento médio de

1. Trabalho recebido em mar./2013 e aceito para publicação em set./2013 (nº registro: PAT 22966).

2. Instituto Federal Goiano (IFG), Campus de Rio Verde, Rio Verde, GO, Brasil.E-mails: paulohagro2010@gmail.com, ajakelaitis@yahoo.com.br, isabellacardoso-rv@hotmail.com, vinicius.tavaresdearaujo@gmail.com, evandro_pedrini@hotmail.com. 
$2.824 \mathrm{~kg} \mathrm{ha}^{-1}$, com destaque para Goiás, como o principal Estado produtor, com 998,9 mil toneladas produzidas e rendimento médio de $3.369 \mathrm{~kg} \mathrm{ha}^{-1}$ (Conab 2012).

Por ser cultivado em diversas regiões do Brasil, o sorgo tem sua produção afetada por diversos fatores, como pragas, doenças e interferência imposta por plantas daninhas.

Quando não controladas adequadamente, as plantas daninhas, além de competirem por água, luz e nutrientes e liberarem substâncias alelopáticas, interferem na colheita e são hospedeiras de diversos insetos-pragas, nematoides e vários agentes patogênicos causadores de doenças (Silva \& Silva 2007). Estima-se que a convivência das plantas daninhas com o sorgo granífero, durante as quatro primeiras semanas após a emergência, pode promover reduções que variam de $40 \%$ a $97 \%$, no rendimento de grãos (Rizzardi et al. 2004).

Para a implantação de programas de manejo integrado de plantas daninhas, torna-se necessária a previsão do impacto da emergência das plantas daninhas e do impacto destas sobre a cultura do sorgo. Também, torna-se imprescindível conhecer os períodos de interferência destas com a cultura (Ciuberkis et al. 2007). Para tanto, três períodos de interferência são descritos na literatura: período anterior à interferência (PAI), período total de prevenção à interferência (PTPI) e período crítico de prevenção à interferência (PCPI). PAI é o período após a emergência, em que plantas daninhas podem conviver com a cultura sem causar prejuízos significativos; PTPI é o período após a emergência que, se exercido o controle, após este, reflete o momento em que a cultura é capaz de prevenir a interferência das plantas daninhas; PCPI é o período que se prolonga do final do PAI até o final do PTPI, em que a convivência das plantas daninhas causa interferência na cultura (Pitelli \& Durigan 1984). A determinação do período crítico pode ser feita considerando-se os estádios fenológicos da cultura ou períodos de tempo após a emergência desta (Amador-Ramírez 2002).

Considerando-se a importância econômica da cultura do sorgo, no Cerrado Goiano, e a necessidade de informações sobre matocompetição, objetivou-se determinar os períodos de interferência das plantas daninhas, em sorgo cultivado na safrinha, no município de Rio Verde (GO).

\section{MATERIAL E MÉTODOS}

Dois ensaios foram instalados em áreas adjacentes, na propriedade agrícola São Tomás Olhos d'Água (17\%48'67'S, 5054'18' W e altitude de $754 \mathrm{~m}$ ), localizada nas proximidades do Instituto Federal Goiano, em Rio Verde, no sudoeste de Goiás, de março a julho de 2012. Os dados de precipitação pluvial e temperatura que ocorreram durante a condução da pesquisa são apresentados na Figura 1.

A análise física e química do solo (Latossolo Vermelho distrófico), à profundidade de $0-0,20 \mathrm{~m}$, apresentou os seguintes valores: $\mathrm{pH}$ (água) $=5,7$; $\mathrm{P}=77,63 \mathrm{mg} \mathrm{dm}^{-3} ; \mathrm{K}=1,45 \mathrm{mmol} \mathrm{dm}^{-3} ; \mathrm{Ca}=$ $69,32 \mathrm{mmol} \mathrm{dm}^{-3} ; \mathrm{Mg}=21,59 \mathrm{mmol} \mathrm{dm}^{-3} ; \mathrm{Al}=$ $0,1 \mathrm{mmol} \mathrm{dm}{ }^{-3} ; \mathrm{V}=61,13 \%$; argila $=457 \mathrm{~g} \mathrm{~kg}^{-1}$; silte $=201 \mathrm{~g} \mathrm{~kg}^{-1}$; areia $=342 \mathrm{~g} \mathrm{~kg}^{-1}$.

Foi adotado o delineamento experimental de blocos casualizados, com quatro repetições. No primeiro ensaio, a cultura foi mantida na presença da comunidade infestante por períodos iniciais crescentes de 0-0, 0-7, 0-14, 0-21, 0-28, 0-35, 0-42, 0-49, 0-56 e 0-112 dias após a emergência (DAE) do sorgo. As unidades experimentais foram mantidas isentas de plantas daninhas, após cada período de convivência. No segundo experimento, o sorgo foi mantido livre das plantas daninhas pelos mesmos períodos e as plantas daninhas emergidas após estes intervalos não foram controladas até o final do ciclo da cultura. As parcelas, conforme os tratamentos, foram mantidas limpas, com capinas semanais realizadas nas entrelinhas, sendo que as plantas daninhas, na linha de semeadura do sorgo, foram removidas manualmente.

Antes da semeadura do sorgo, a área experimental foi cultivada com soja, em semeadura direta. A colheita desta foi realizada no dia 01/03/2012 e,

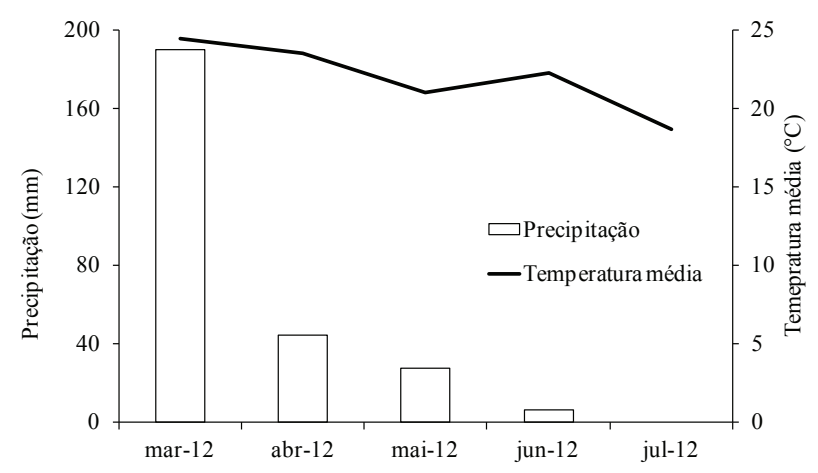

Figura 1. Precipitação pluvial e temperatura média do ar mensais, de março a julho de 2012 (Rio Verde, GO). 
sete dias após, procedeu-se à semeadura do sorgo granífero, também em semeadura direta, utilizando-se uma semeadora-adubadora tratorizada. Antes da semeadura do sorgo, efetuou-se o lançamento de um quadrado amostral de $0,25 \mathrm{~m}^{2}$ em oito pontos, ao acaso, na área, e as espécies de plantas daninhas mais frequentes foram: Amaranthus lividus L., Bidens pilosa L., Emilia sonchifolia (Linn.) DC, Nicandra physaloides (L.) Gaertn., Cyperus rotundus L., Phyllanthus tenellus Roxb., Sida rhombifolia L., Portulaca oleracea L., Commelina benghalensis L., Cenchrus echinatus L., Digitaria horizontalis Willd, Eleusine indica (L.) Gaertn. e Urochloa decumbens Stapf, as quais foram controladas em pré-plantio com glyphosate, na dose de $960 \mathrm{~g}$ do i.a. ha- ${ }^{-1}$.

O sorgo (DK550) foi semeado no espaçamento de $0,5 \mathrm{~m}$ entre as linhas, com população de 10 sementes por metro, semeadas à profundidade de $3,0 \mathrm{~cm}$. Foram utilizados, como adubação de semeadura, $160 \mathrm{~kg} \mathrm{ha}^{-1}$ de N-P-K (formulação 10-20-20) e, em cobertura, foram aplicados $100 \mathrm{~kg} \mathrm{ha}^{-1}$ de $\mathrm{N}$, utilizando-se sulfato de amônia, aos $35 \mathrm{DAE}$, o qual foi distribuído na linha de cultivo do sorgo. As parcelas experimentais possuíam $8,0 \mathrm{~m}^{2}$, constituídos por quatro linhas de sorgo, com 4,0 m de comprimento, considerando-se, como área útil, as duas linhas centrais, descartando-se $0,5 \mathrm{~m}$ das extremidades, totalizando $3,0 \mathrm{~m}^{2}$.

Para a avaliação da comunidade de plantas daninhas, efetuou-se o lançamento, ao acaso, de dois quadrados amostrais de $0,25 \mathrm{~m}^{2}$ por parcela, após os períodos de convivência, e, em seguida, foi realizada a identificação e contagem das plantas daninhas. No final de cada período de convivência, as plantas daninhas foram coletadas e separadas por espécie, sendo acondicionadas em sacos de papel e levadas para estufa com ventilação forçada de ar de $70^{\circ} \mathrm{C}$, $\pm 5^{\circ} \mathrm{C}$, por 72 horas, até atingirem peso constante, e, em seguida, pesadas.

Antes da colheita de grãos da cultura, foram determinados, em cinco plantas de sorgo, na área útil, o diâmetro de colmo, com auxílio de um paquímetro, e a altura de plantas, do solo até a inserção da folha-bandeira. Para a determinação do rendimento de grãos do sorgo, procedeu-se ao corte manual das panículas, debulha e limpeza com peneira, manualmente, e, em seguida, à pesagem dos grãos trilhados da área útil de cada parcela, determinando-se o rendimento de grãos por hectare e a massa de mil grãos, corrigida para $13 \%$ de umidade. A massa de mil grãos e o teor de umidade para correção foram obtidos após secagem em estufa de circulação forçada de ar a $105^{\circ} \mathrm{C}, \pm 5^{\circ} \mathrm{C}$, por 24 horas.

A análise estatística foi realizada separadamente, para cada experimento. Os resultados foram submetidos à análise de variância, e, quando significativos, à análise de regressão por modelos não-lineares. $\mathrm{O}$ modelo utilizado foi $\mathrm{Y}=\mathrm{y} 0+\mathrm{a} /[1+\exp (-(\mathrm{x}-\mathrm{x} 0) / \mathrm{b}]$, em que $\mathrm{Y}=$ variável resposta; $\mathrm{y} 0=$ produtividade mínima obtida na testemunha infestada; $\mathrm{x} 0=$ número de dias em que ocorre $50 \%$ na redução; $\mathrm{x}=$ número de dias após a emergência da cultura; $a=$ coeficiente que representa $o$ valor máximo menos o valor mínimo obtido da testemunha limpa e estimado pelo modelo; $b=$ declividade da curva. Dos modelos ajustados para o rendimento de grãos, foram determinados o período anterior à interferência (PAI), período total de prevenção à interferência (PTPI) e período crítico de prevenção à interferência (PCPI), adotando-se 5\% de perdas na produtividade. Adotou-se 5\% de significância estatística.

\section{RESULTADOS E DISCUSSÃO}

Observou-se que a massa seca e a densidade da comunidade infestante foram influenciadas pelos períodos avaliados, bem como as variáveis da cultura representadas pela altura das plantas, diâmetro de colmo, rendimento e massa de mil grãos.

A comunidade infestante foi composta por $41,03 \%$ de monocotiledôneas e $58,97 \%$ de dicotiledôneas, constituída por nove famílias botânicas e treze espécies. As espécies encontradas, em ambos os ensaios, foram: Amaranthus lividus (Amaranthaceae), Bidens pilosa e Emilia sonchifolia (Asteraceae), Nicandra physaloides (Solanaceae), Cyperus rotundus (Cyperaceae), Phyllanthus tenellus (Phyllanthaceae), Sida rombipholia (Malvaceae), Portulaca oleraceae (Portulacaceae), Commelina benghalensis (Commelineaceae) e Cenchrus echinatus, Digitaria horizontalis, Eleusine indica e Urochoa decumbens, pertencentes à família Poaceae.

A família Poaceae foi a mais diversificada, neste trabalho, e as demais espécies encontradas também são representativas no agrossistema da cultura do sorgo, conforme pesquisa feita por Rodrigues et al. (2010), em Botucatu (SP). Estes autores constataram, também, que, entre as monocotiledôneas, as famílias que mais ocorreram, nesta cultura, foram Poaceae, Cyperaceae e Commelineacea, e, entre as dicotiledôneas, a Asteraceae. 
Para a densidade de plantas daninhas, em função dos períodos de convivência e de controle (Figura 2), de acordo com o modelo, quando a cultura do sorgo foi mantida por períodos decrescentes de convivência com a comunidade infestante, foram observados aumentos, principalmente a partir dos 21 DAE, até próximo aos 56 DAE, atingindo, em média, 70 plantas $\mathrm{m}^{-2}$, e, somente a partir deste período, houve estabilidade na densidade da comunidade infestante até a colheita. Diferentemente, em outros trabalhos com culturas anuais, feitos para determinar os períodos de interferência de plantas daninhas, foram verificadas maiores densidades de indivíduos no início dos períodos de convivência e, em seguida, redução significativa destas, em função da competição intraespecífica e interespecífica, que se estabelecem à medida em que as espécies se desenvolvem (Brighenti et al. 2004, Salgado et al. 2007, Rodrigues et al. 2010).

O aumento da população de plantas daninhas, no início do ciclo do sorgo, pode estar associado à desuniformidade no processo germinativo das plantas daninhas, devido à presença da cobertura vegetal morta da cultura da soja, anteriormente cultivada na mesma área, e das plantas daninhas dessecadas, ocorrendo, assim, efeitos físicos da cobertura vegetal morta sobre a comunidade infestante. Por outro lado, o estabelecimento da densidade pode estar associado aos efeitos do sombreamento, resultando na redução da capacidade das plantas daninhas em sobressaírem mediante a dominância do sorgo, e à redução da pluviosidade no final do ciclo da cultura (Figura 1),

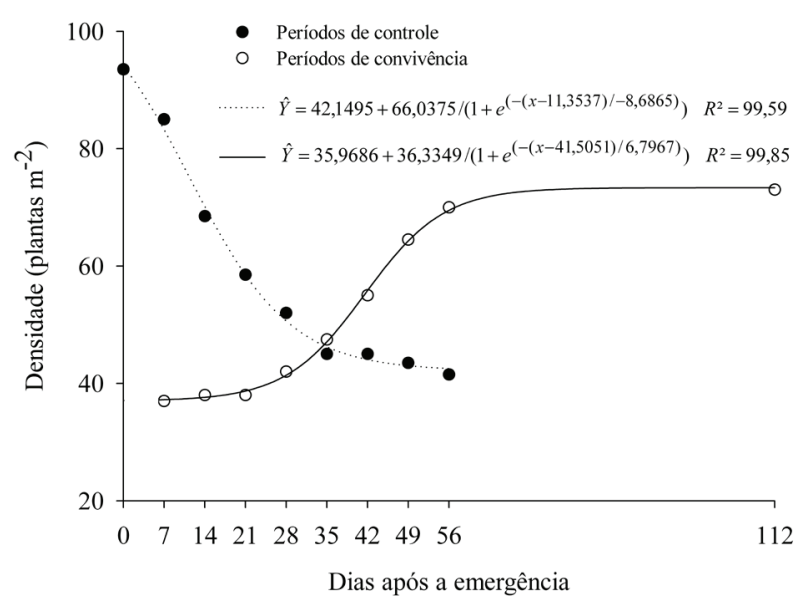

Figura 2. Densidade de plantas daninhas, em função dos períodos de convivência e de controle destas, na cultura do sorgo (Rio Verde, GO, 2012). que diminui o fluxo de emergência das plântulas do banco de sementes, conforme observado com a redução na densidade de indivíduos, com o aumento dos períodos de controle (Figura 2).

A massa seca acumulada da comunidade infestante apresentou comportamento semelhante à densidade de indivíduos (Figura 3). Nos períodos de convivência, a massa seca aumentou, significativamente, de 38,42 $\mathrm{g} \mathrm{m}^{-2}$, aos 28 DAE, para $68,87 \mathrm{~g} \mathrm{~m}^{-2}$, aos 56 DAE (Figura 3). Da emergência do sorgo, aos $21 \mathrm{DAE}$ e após os $56 \mathrm{DAE}$, até atingir a colheita, houve estabilidade no acúmulo de massa seca. Assim, no início do ciclo da cultura, este desempenho pode ser explicado pala baixa densidade de indivíduos na comunidade infestante (Figura 2). A estagnação no acúmulo de massa seca, após os 56 DAE, reside no fato de que algumas espécies de plantas daninhas (em especial as dicotiledôneas) tenham finalizado seu ciclo antes da última avaliação, ou do fim do ciclo fenológico do sorgo, bem como pelo fechamento do dossel pela cultura, não permitindo, desta maneira, a germinação e o desenvolvimento da comunidade infestante, pelo impedimento da captura de recursos do meio pelas plantas daninhas, principalmente a radiação solar.

Nos períodos relacionados ao controle, a massa seca das plantas daninhas diminuiu, significativamente, quando o controle foi realizado até os 35 DAE, estabilizando-se até os 56 DAE (Figura 4). O comportamento da massa seca acumulada pelas plantas daninhas, em função dos períodos de controle e convivência com o sorgo, corrobora os resultados

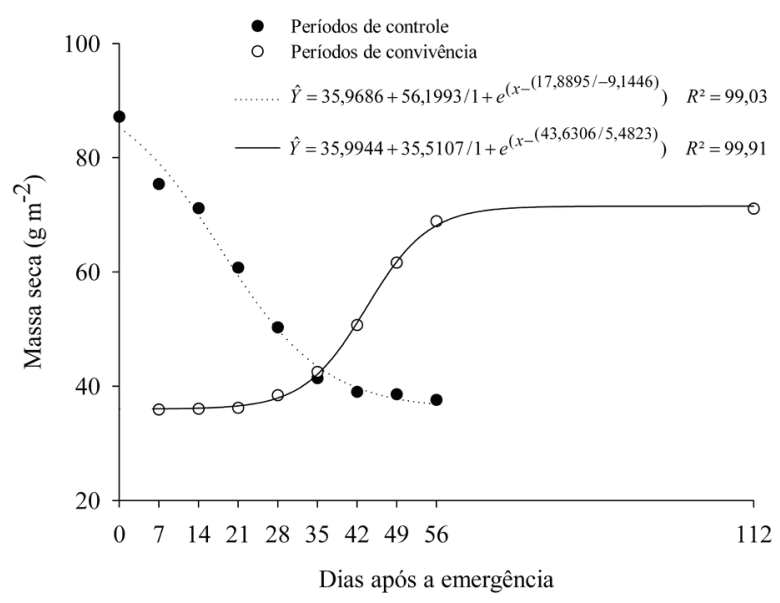

Figura 3. Massa seca de plantas daninhas, em função dos períodos de convivência e de controle destas, na cultura do sorgo (Rio Verde, GO, 2012). 
encontrados em outras pesquisas, em culturas como a soja (Mello et al. 2001), algodão (Salgado et al. 2002), girassol (Briguenti et al. 2004), arroz (Silva \& Durigan 2009) e sorgo (Rodrigues et al. 2010).

A convivência de plantas daninhas com a cultura, até os $21 \mathrm{DAE}$, não afetou a altura das plantas de sorgo. Todavia, a partir deste período, observou-se redução significativa no porte das plantas, até os 56 DAE, perdurando até a colheita (Figura 4). Da mesma forma, quando o controle de plantas daninhas na cultura não é realizado antes dos $35 \mathrm{DAE}$, observa-se redução no porte das plantas, mas, à medida em que a cultura permanece limpa até este período, a comunidade infestante não afeta a altura das plantas até o final do ciclo fenológico.

Nesta pesquisa, a diferença na altura das plantas, considerando-se a cultura limpa ou infestada por plantas daninhas, por todo o ciclo das plantas, foi de, aproximadamente, $10,0 \mathrm{~cm}$. Comportamento semelhante foi observado com o diâmetro do colmo de sorgo, quando em convivência com a comunidade infestante (Figura 5). A partir dos 21 DAE, observou-se que cada dia de convivência das plantas daninhas com o sorgo proporcionou redução no diâmetro do colmo, sendo este efeito estendido até a colheita da cultura. Da mesma forma, quando o controle foi estendido até os $56 \mathrm{DAE}$, observou-se que o diâmetro do colmo não foi mais afetado pelas plantas daninhas que se estabeleceram a partir desta data, em decorrência da competição exercida pela cultura. Além de servir de base de sustentação da planta, assegurando a produção, esta variável é

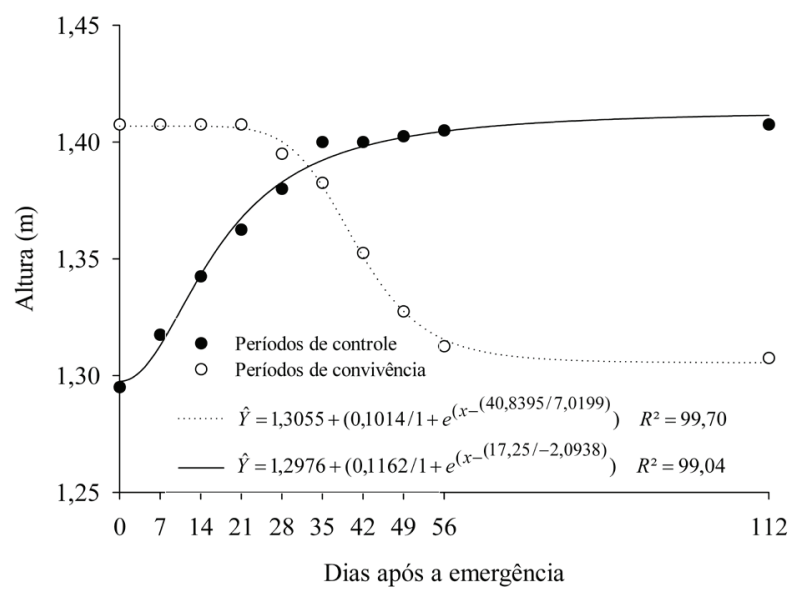

Figura 4. Altura de plantas de sorgo, em função dos períodos de convivência e de controle de plantas daninhas na cultura (Rio Verde, GO, 2012). um parâmetro morfológico importante na colheita mecanizada, por evitar o acamamento das plantas, durante a colheita, além de evitar o tombamento de plantas, por ação do vento (Fornasieri Filho \& Fornasieri 2009).

Quanto à massa de mil grãos, observou-se que, com o aumento dos períodos de convivência das plantas daninhas com a cultura, houve redução a partir dos $28 \mathrm{DAE}$, com queda acentuada até os 56 DAE, estabilizando-se até o momento da colheita (Figura 6). A interferência das plantas daninhas contribuiu para redução de $20,5 \%$, nesta variável, comparando-se as parcelas infestadas com as parcelas limpas, por todo o ciclo da cultura.

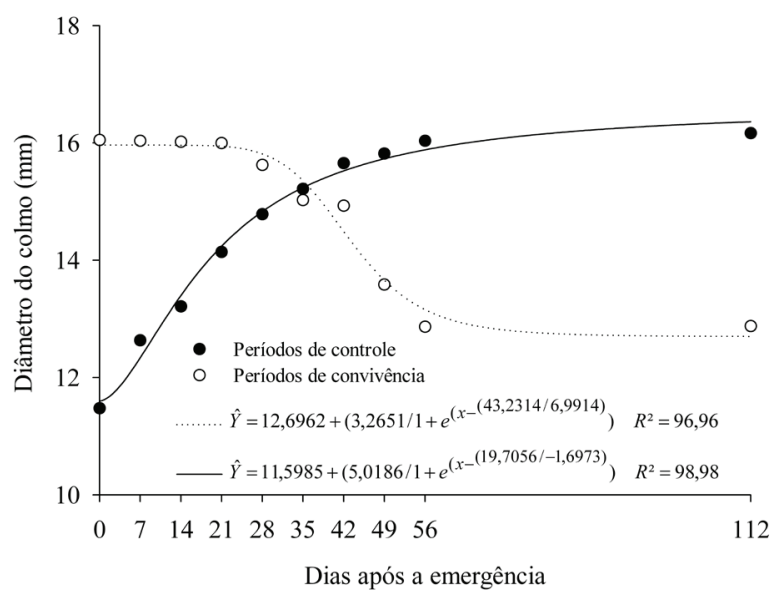

Figura 5. Diâmetro do colmo de plantas de sorgo, em função dos períodos de convivência e de controle de plantas daninhas na cultura (Rio Verde, GO, 2012).

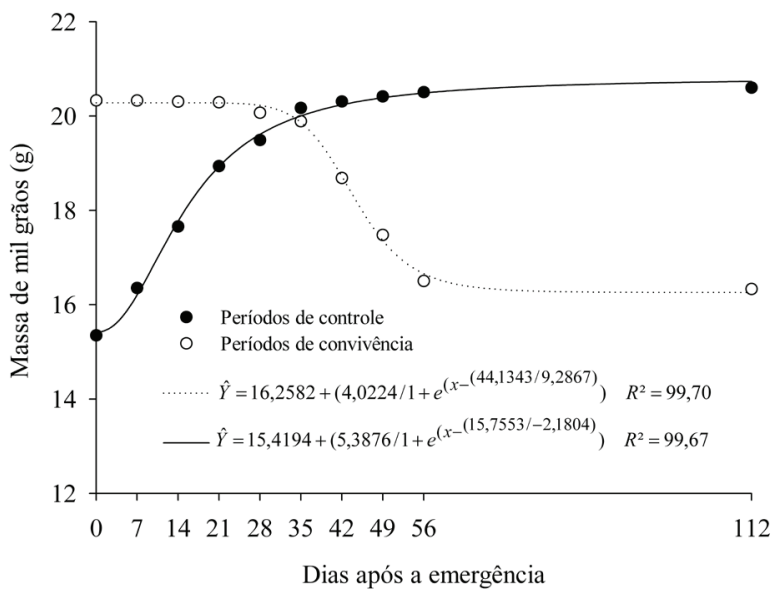

Figura 6. Massa de mil grãos de sorgo, em função dos períodos de convivência e de controle de plantas daninhas na cultura (Rio Verde, GO, 2012). 
A redução na massa de mil grãos, quando a cultura convive com plantas daninhas, ocorre, principalmente, por recursos ligados à competição, onde as plantas direcionam os assimilados produzidos para o seu crescimento, resultando em déficit para o enchimento do órgão vegetativo de reserva. Ademais, a convivência com as plantas daninhas, na fase reprodutiva da cultura, faz com que se crie um ambiente com alta umidade, o que favorece o surgimento de patógenos nas estruturas reprodutivas, resultando em depreciação na massa de grãos (Gazziero et al. 2004). Nesta pesquisa, observou-se que o controle foi eficiente, quando realizado até os 35 DAE, e que a cultura estabelecida a partir daí é capaz de suprimir a interferência das plantas daninhas, quanto a esta variável.

Os dados de rendimento de grãos, para os períodos de convivência e de controle de plantas daninhas, estão inseridos na Figura 7. Comumente, a perda aceitável decorrente da interferência de plantas daninhas no rendimento de grãos do sorgo é variável para cada agrossistema, de acordo com fatores como o custo de controle ou perdas na colheita.

Considerando-se 5\% de tolerância na redução do rendimento de grãos, verificou-se que o PAI ocorreu até os 23 DAE e o PTPI até os 42 DAE do sorgo. Desta forma, o PCPI situou-se entre 23 e

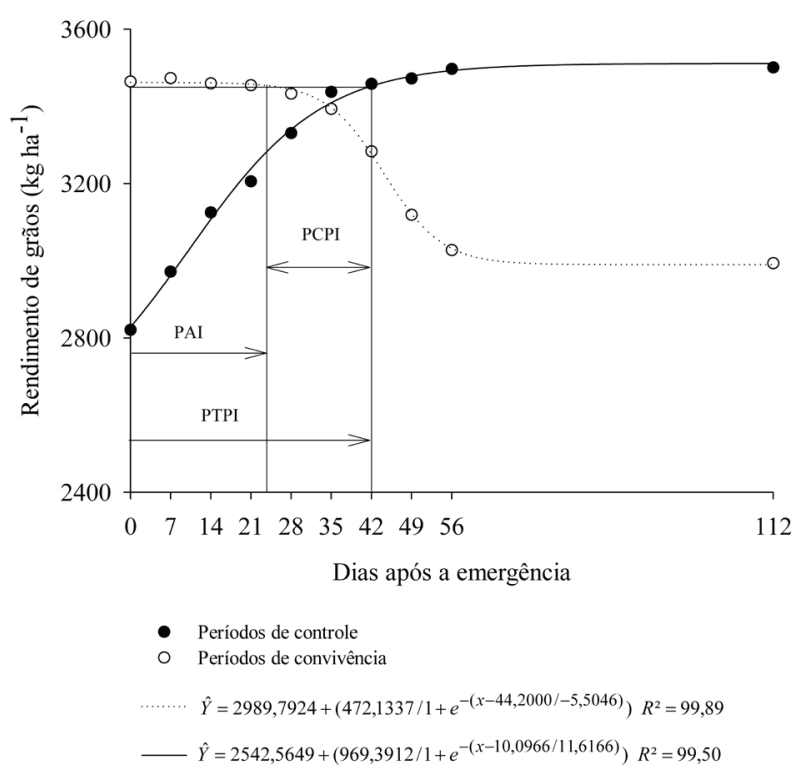

Figura 7. Rendimento de grãos de sorgo, em função dos períodos de convivência e de controle de plantas daninhas na cultura (Rio Verde, GO, 2012). O PAI foi até os 23 dias, o PTPI até os 42 dias e o PCPI dos 23 aos 42 dias após o rendimento de grãos do sorgo, estimando-se $5 \%$ de perdas.
42 DAE. Sendo assim, para que não ocorram perdas significativas no rendimento de grãos da cultura, é necessário que, neste período, a mesma fique livre de plantas daninhas, evitando-se perdas ou o uso desnecessário de herbicidas.

Nesta pesquisa, a redução no rendimento de grãos, atribuído à comunidade infestante, foi, em média, de $19,5 \%$, nas parcelas onde a cultura não conviveu com as plantas daninhas, se comparadas às parcelas infestadas por todo o ciclo da cultura. Em trabalho realizado por Rodrigues et al. (2010), na cultura do sorgo, os autores verificaram perdas de $89,6 \%$, quando a cultura conviveu com a comunidade infestante por todo o seu ciclo, se comparada às parcelas isentas de competição, demonstrando que a intensidade de interferência é decorrente de fatores como solo, clima, cultivar, práticas de cultivo e espécies de plantas daninhas.

Observou-se que o PAI foi o período em que a ocorrência de plantas daninhas não ocasionou perdas significativas no rendimento da cultura, pois ainda não se instalou a competição, sendo que este período se deu nas três primeiras semanas após a emergência do sorgo, quando as plantas encontravam-se com cinco folhas emitidas. Verificou-se, ainda, que o final deste período é o momento adequado para o controle, pois as plantas daninhas se encontram no início do desenvolvimento, apresentando baixa densidade de indivíduos e acúmulo de massa seca, quando as técnicas de controle empregadas são geralmente mais eficientes. Andres et al. (2009), em pesquisa realizada com a cultura do sorgo cultivado em terras baixas, em clima temperado, verificaram que o período adequado para realizar o controle de plantas daninhas situa-se entre a emissão da terceira e da sétima folha da planta.

Nesta pesquisa, a partir dos 23 DAE (início do PCPI), verificou-se que houve aumento progressivo na densidade e no acúmulo de massa seca, onde as plantas daninhas convivem com a cultura, exercendo o processo de competição pelos recursos presentes no meio e diminuindo o rendimento da cultura. Para a condição local de cultivo, há necessidade de que os herbicidas utilizados na cultura apresentem atividade residual até os $42 \mathrm{DAE}$ (estádio fenológico de nove folhas emitidas), para assegurar o rendimento do sorgo, uma vez que, a partir deste período, as plantas daninhas que emergirem e se instalarem juntamente com a cultura não ocasionarão perdas significativas na produtividade. 


\section{CONCLUSÕES}

1. Plantas daninhas convivendo com a cultura afetaram, negativamente, a altura das plantas, diâmetro de colmo, rendimento de grãos e massa de mil grãos das plantas de sorgo.

2. Para o sorgo DK 550, cultivado em safrinha, o PAI foi até os 23 DAE, o PTPI até os 42 DAE e o PCPI de 23 a 42 DAE do sorgo.

\section{REFERENNCIAS}

AMADOR-RAMÍREZ, M. D. Critical period of weed control in transplanted chili pepper. Weed Research, Oxford, v. 42, n. 3, p. 203-209, 2002.

ANDRES, A. et al. Períodos de interferência de plantas daninhas na cultura do sorgo forrageiro em terras baixas. Planta Daninha, Viçosa, v. 27, n. 2, p. 229-234, 2009.

BRIGUENTI, A. M. et al. Períodos de interferência de plantas daninhas na cultura do girassol. Planta Daninha, Viçosa, v. 22, n. 2, p. 251-157, 2004.

CIUBERKIS, S. et al. Effect of weed emergence time and intervals of weed and crop competition on potato yield. Weed Technology, Lawrence, v. 21, n. 1, p. 213-218, 2007.

COMPANHIA NACIONAL DE ABASTECIMENTO (Conab). Acompanhamento da safra brasileira: grãos 2012/2013. 2012. Disponível em: < http://www.conab.gov. br/OlalaCMS/uploads/arquivos/13_02_08_17_24_51_ boletim_fevereiro_2013.pdf $>$. Acesso em: 04 mar. 2013 . FORNASIERI FILHO, D.; FORNASIERI, J. L. Manual da cultura do sorgo. Jaboticabal: Funep, 2009.

GAZZIERO, D. L. P. et al. Manejo e controle de plantas daninhas em soja. In: VARGAS, L.; ROMAN, E. S. Manual de manejo e controle de plantas daninhas. Bento Gonçalves: Embrapa Uva e Vinho, 2004. p. 595-635.

MELLO, H. B. et al. Interferência das plantas daninhas na cultura da soja cultivada em dois espaçamentos entre linhas. Planta Daninha, Viçosa, v. 19, n. 2, p. 187-191, 2001.

PITELLI, R. A.; DURIGAN, J. C. Terminologia para períodos de controle e de convivência das plantas daninhas em culturas anuais e bianuais. In: CONGRESSO BRASILEIRO DE HERBICIDAS E PLANTAS DANINHAS, 15., 1984, Belo Horizonte. Resumos... Piracicaba: Augegraf, 1984. p. 37.

RIZZARDI, M. A.; KARAM, D.; CRUZ, M. B. Manejo de plantas daninhas em milho e sorgo. In: VARGAS, L.; ROMAM, E. S. Manual de manejo e controle de plantas daninhas. Bento Gonçalves: Embrapa Uva e Vinho, 2004. p. 571-594.
RODRIGUES, A. C. P. et al. Períodos de interferência de plantas daninhas na cultura do sorgo. Planta Daninha, Viçosa, v. 28, n. 1, p. 23-31, 2010.

SALGADO, T. P. et al. Interferência das plantas daninhas no feijoeiro carioca. Planta Daninha, Viçosa, v. 25, n. 3, p. 443-448, 2007.

SALGADO, T. P. et al. Períodos de interferência das plantas daninhas na cultura do algodoeiro (Gossypium hirsutum). Planta Daninha, Viçosa, v. 20, n. 3, p. 373379, 2002.

SILVA, A. A.; SILVA, F. J. Tópicos em manejo de plantas daninhas. Viçosa: Ed. da UFV, 2007.

SILVA, M. R.; DURIGAN, J. C. Períodos de interferência de plantas daninhas na cultura do arroz de terras altas: II. Cultivar Caiapó. Bragantia, Campinas, v. 68, n. 2, p. 373-379, 2009.

ZAGO, C. P. Utilização do sorgo na alimentação de ruminantes. In: EMPRESA BRASILEIRA DE PESQUISA AGROPECUÁRIA. Manejo cultural do sorgo para forragem. Sete Lagoas: Embrapa, 1997. p. 9-26. (Circular técnica, 17). 